\title{
Práticas complementares de saúde e os desafios de sua aplicabilidade no hospital: visão de enfermeiros
}

Complementary health practices and challenges of its applicability in hospital: nurses' point of view

Prácticas complementarias de salud y desafíos de su aplicabilidad en el hospital: visión de enfermeros

\section{Suzane Cristina Costa Melo', Raíra Gomes de Santana', Déborah Cardozo dos Santos', Neide Aparecida Titonelli Alvim'}

' Universidade Federal do Rio de Janeiro, Escola de Enfermagem Anna Nery, Curso de Graduação em Enfermagem. Rio de Janeiro-RJ, Brasil.

\author{
Submissão: 21-06-2012 Aprovação: 22-11-2013
}

\section{RESUMO}

Pesquisa de abordagem qualitativa, descritivo-exploratória, com o objetivo de descrever o conjunto de concepções e saberes que orientam o emprego de práticas integrativas e complementares de saúde (PICS) por enfermeiros; e analisar os desafios que se apresentam à aplicabilidade dessas terapias por enfermeiros no contexto hospitalar. Os sujeitos da pesquisa foram enfermeiros de instituições públicas hospitalares do Rio de Janeiro. A coleta de dados foi feita através de entrevista semiestruturada e técnica de criatividade e sensibilidade denominada Almanaque. Os resultados mostram que a hegemonia do modelo biomédico na formação e atuação dos profissionais de saúde dificulta a aplicação de PICS no hospital. Porém, à medida que esse modelo não dá conta da complexidade do ser humano, emerge a possibilidade de compartilhamento com PICS no cuidado, visando à integralidade do ser humano.

Descritores: Cuidado de Enfermagem; Tecnologia; Terapias Complementares.

\begin{abstract}
This is a qualitative, descriptive and exploratory research, aiming to describe the set of ideas and knowledge that guide the use of complementary and integrative health practices (CIHP) by nurses, and analyze the challenges facing the applicability of these therapies by nurses in the hospital setting. The subjects were nurses in public hospital institutions of Rio de Janeiro. Data collection was done through semi-structured interviews and a technique of creativity and sensibility called Almanac. The results showed that the hegemony of the biomedical model in the formation and performance of health professionals hinders implementation of CIHP in hospital. However, as this model does not account for the complexity of the human being emerges the possibility of sharing with CIHP in care aiming, therefore, at comprehensiveness of the human being.
\end{abstract}

Key words: Nursing Care; Health Technology; Complementary Therapies.

\section{RESUMEN}

Investigación con enfoque cualitativo, descriptivo y exploratorio, con el objetivo de describir el conjunto de conceptos y conocimientos que guían las prácticas de empleo de la salud complementaria e integral (PICS) por enfermeros; y analizar los desafíos que enfrentan a la aplicación de estas terapias por los enfermeros en los hospitales. Los sujetos fueron enfermeros de los hospitales públicos de Río de Janeiro. La cosecha de datos se realizó mediante la técnica de entrevista semi-estructurada y la creatividad y la sensibilidad Ilamada almanaque. Los resultados muestran que la hegemonía del modelo biomédico en la formación y el rendimiento de los trabajadores de salud obstaculiza la aplicación de PICS en el hospital. Sin embargo, como este modelo no tiene en cuenta la complejidad del ser humano surge la posibilidad de compartir con el cuidado PICS, con el objetivo de todo el ser humano.

Palabras claves: Cuidados en Enfermería; Tecnología de La Salud; Terapias Complementarias. 


\section{INTRODUÇÃO}

No decorrer da história da ciência ocidental moderna, a Biologia e a Medicina sempre caminharam juntas em seu desenvolvimento. Na base do pensamento biológico, por influência de Descartes, está a concepção cartesiana na qual se reduz os organismos vivos a seus menores constituintes. Assim sendo, é natural que uma vez que esses conceitos tenham sido firmados nas bases da Biologia, a Medicina tenha aderido de igual forma a esses princípios. A influência do modelo cartesiano sobre o pensamento médico deu origem ao chamado modelo biomédico ${ }^{(1)}$.

O movimento de ruptura com as maneiras de conceber o organismo humano, que antecedeu a ciência moderna, deu-se com a Anatomia, através da qual se formou uma nova racionalidade médica cujo mecanismo fisiologista era fundamentado no modelo clássico. A partir de tal concepção, a vida humana deixou de ser o objeto central da prática médica e o homem passou a ser visto como máquina composta por diferentes e minuciosas partes. Os hospitais passaram a ser organizados como espaço clínico de uma ciência voltada às patologias, onde o corpo humano era a sede das doenças e estas, as entidades patológicas ${ }^{(2)}$.

A visão do ser humano tornou-se fragmentada. Com a utilização desse modelo, os médicos passaram a ver o corpo humano como uma máquina que podia ser analisada em termos de suas peças e assumiram para si o papel de intervir, física ou quimicamente, para consertar o defeito de um mecanismo ${ }^{(1)}$. Desta forma, o poder hegemônico passou a ser do profissional médico, uma vez que todas as intervenções propostas deveriam passar pelo seu crivo para serem aprovadas.

O modelo biomédico vê o corpo humano como uma máquina muito complexa, com partes que se inter-relacionam obedecendo a leis naturais ${ }^{(2)}$. Tal modelo tem se caracterizado por uma "explicação unicausal da doença, pelo biologicismo, fragmentação, mecanicismo, nosocentrismo, recuperação e reabilitação, tecnicismo e especialização"(3) e é este modelo que tem dominado o contexto hospitalar. Mesmo quando o profissional intenciona ver o cliente como um todo unificado, sua intervenção acaba por retornar ao modelo reducionista devido, principalmente, à sua formação acadêmica e ao domínio biomédico nos diferentes espaços de atendimento à saúde, em especial, o hospitalar.

O centro da atenção do profissional, segundo este modelo, é o indivíduo doente e as ações de recuperação e reabilitação da doença são priorizadas em detrimento das ações de promoção e proteção à saúde. Desta forma, a "troca da globalidade pela especialização atenuou a compreensão holística do ser humano"(3). Se, de um lado, não podemos ignorar que os avanços técnico-científicos produzidos pelo modelo biomédico contribuíram, sobremaneira, na eliminação ou controle de determinadas doenças, como, por exemplo, as de natureza bacteriana; nas cirurgias do coração; nos transplantes de órgãos, entre outros; por outro, aparentemente, esse modelo não vem dando conta da totalidade de saúde do ser humano, tendo em vista as várias dimensões resultantes da interação que ocorre entre os diversos componentes físicos, sociais, históricos e culturais da natureza do homem ${ }^{(4)}$.
No campo da saúde há, hoje, a emergência de novas abordagens no que tange à questão do adoecimento e às formas de nele intervir, tais como a clínica ampliada, a humanização do atendimento, as discussões sobre a integralidade em saúde e a produção do cuidado com vistas à transformação do modelo técnico-assistencial. Juntamente a tais abordagens, tem-se observado nos últimos anos uma crescente aceitação das terapias complementares em nossa sociedade.

Essas terapias possuem bases teórico-filosóficas que se contrapõem ao modelo convencional, o biomédico, cujo alicerce é o pensamento cartesiano. Seu enfoque visa um olhar holístico do ser humano, integrando os sistemas físico, psicológico e social. Portanto, refutam a concepção do ser humano constituído de partes isoladas que podem ser analisadas independentemente, entendendo-o pela interdependência dessas partes que formam sua integralidade.

Em 2006, o Ministério da Saúde implantou a Política Nacional de Práticas Integrativas e Complementares (PNPIC), que rege a inserção destas práticas no Sistema Único de Saúde, dispondo sobre sua implantação no contexto nacional ${ }^{(5)}$. O campo das PICS contempla sistemas médicos complexos e recursos terapêuticos conhecidos sob várias denominações, como tradicionais, complementares, integrativas, alternativas ou não convencionais. Esses sistemas buscam a estimulação de

mecanismos naturais de prevenção de agravos e recuperação da saúde através de tecnologias eficazes e seguras. Elas enfatizam a escuta acolhedora, o desenvolvimento do vínculo terapêutico e a integração do ser humano com o meio ambiente e a sociedade ${ }^{(5)}$.

O estímulo da Organização Mundial de Saúde fez com que o Brasil passasse a ser um país de vanguarda na sua utilização no sistema oficial de saúde no âmbito das Américas, assegurando aos usuários do SUS o acesso à medicina tradicional chinesa/acupuntura, homeopatia, plantas medicinais e fitoterapia, termalismo social/crenoterapia ${ }^{(5)}$. No entanto, ao mesmo tempo em que a procura por métodos complementares de cuidado se torna crescente, sua inserção no meio hospitalar torna-se um grande desafio pelo fato de ir de encontro aos saberes e práticas cunhadas ao modelo biomédico próprias deste contexto.

O cuidado de enfermagem sofre influência desse modelo, dominante na saúde, especialmente, no hospital, espaço de objetividade técnica, onde imperam formas impositivas de abordagem e intervenção. Desse modo, vemos que há um grande "esforço da biomedicina em incluir os sintomas físicos sem causas explicáveis dentro das suas inúmeras categorizações, ou seja, tornar o subjetivo objetivo e transformar o invisível em visível"(6). Mas a completude do saber biomédico está diminuindo nos círculos intermediários, porque está reduzindo a máquina humana em peças cada vez menores ${ }^{(7)}$.

Os saberes e práticas que seguem a orientação biomédica se distanciam dos princípios que orientam as PICS. Em termos científicos modernos, o processo de cura através de PICS representa a resposta coordenada do organismo integrado às influências ambientais causadoras de tensão. Isto porque, 
“Essa concepção de cura envolve certo número de conceitos que transcendem a divisão cartesiana e que não podem ser formuladas de acordo com a estrutura da ciência médica

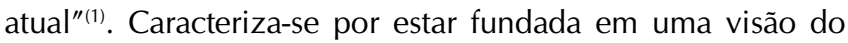
indivíduo de forma totalizante. No Brasil, muitas PICS estão sendo discutidas e incorporadas nos serviços oficiais de saúde, especialmente, a partir da Portaria do Ministério da Saúde mencionada, inclusive aplicadas por enfermeiros no cuidado. No entanto, há dúvidas a respeito de que tipo de saber sustenta a prática do enfermeiro no emprego de PICS, e que desafios se apresentam à sua aplicabilidade no contexto do cuidado hospitalar.

Questiona-se até que ponto o modelo biomédico, dominante no hospital, pode influenciar na aplicabilidade de PICS tornando-as técnicas fragmentadas e isoladas, deslocando-as, portanto, de suas racionalidades tradicionais - filosófica e cultural. Assim sendo, objetivou-se descrever o conjunto de concepções e saberes que orientam o emprego de práticas integrativas e complementares de saúde por enfermeiros e analisar os desafios que se apresentam à aplicabilidade dessas terapias por enfermeiros no contexto hospitalar.

\section{METODOLOGIA}

Pesquisa de campo, do tipo qualitativo, exploratório e descritivo. A pesquisa qualitativa "traduz, à sua maneira, as articulações entre o singular, o individual e o coletivo que estão presentes nos processos de saúde-doença"(8). Dessa forma, possibilita traduzir um pouco da experiência humana vivenciada por cada sujeito participante.

O cenário da pesquisa constituiu-se de hospitais públicos da cidade do Rio de Janeiro, de esfera municipal, estadual e federal. Os sujeitos da pesquisa foram 15 enfermeiros que atuavam nestes hospitais e que aplicavam ao menos uma das seguintes PICS como recurso terapêutico no cuidado: Rei$k i$, shiatsu, acupuntura, fitoterapia, musicoterapia, florais e cromoterapia.

Em respeito à Resolução n 466/2012, que regulamenta as pesquisas feitas com seres humanos, o projeto foi aprovado pelo Comitê de Ética e Pesquisa da Escola de Enfermagem Anna Nery/ Hospital Escola São Francisco de Assis, através do protocolo $n^{\circ}$ 031/11. Todos os sujeitos assinaram o Termo de Consentimento Livre e Esclarecido após devidamente informados sobre o caráter voluntário de sua participação; sobre a garantia de sua identidade não ser revelada; e o direito de desistir de sua participação em qualquer momento da pesquisa. Do mesmo modo, foram informados que a pesquisa não previa nenhum custo assim como nenhum tipo de compensação financeira por sua participação. A identificação dos sujeitos se deu através de números arábicos sequenciais de acordo com a produção de dados e da enunciação da terapêutica aplicada por cada um deles.

Para produção de dados foram utilizadas a Técnica de Criatividade e Sensibilidade (TCS), denominada "Almanaque", juntamente com a entrevista semiestruturada. A TCS ajuda a apreender o mundo imaginário do sujeito, de modo que transcende a racionalidade e as diversidades das experiências e vivências com o emergir das expressões de criatividade e sensibilidade. Dessa forma, a expressão da subjetividade ganha forma concreta através do diálogo entre o pesquisador e o sujeito $^{(9)}$.

A TCS Almanaque consiste em refletir sobre questões relacionadas ao tema central do estudo que neste caso versou sobre as PICS e sua aplicabilidade por enfermeiros no cuidado de enfermagem. Para a atividade, utilizou-se recorte e colagem de gravuras, desenhos, palavras ou frases que tenham algum significado para o sujeito. O pesquisador fornece gravuras e palavras que apresentam pessoas ou situações em diversos contextos, e o sujeito escolhe quais possuem maior representatividade para si, a fim de compor seu "Almanaque". São fornecidos ainda materiais adicionais pelo pesquisador, como cola, tesoura, folha de papel e canetas coloridas para que o sujeito expresse, ao máximo, sua criatividade em responder as questões propostas. Após a confecção de seu Almanaque, o sujeito o apresenta ao pesquisador, explicitando e justificando o motivo de suas escolhas, abrindo ao diálogo que ocorre concomitantemente à entrevista semiestruturada. Nesta pesquisa, as questões apresentadas para a confecção do Almanaque foram: 1) O que vocês pensam sobre a aplicabilidade de PICS no cuidado hospitalar? 2) Que saberes orientam sua prática nesse contexto? A entrevista semiestruturada levantou questões complementares às resultantes da TCS Almanaque, pontuando dificuldades e facilidades do emprego de PICS por enfermeiros tendo em vista as características próprias do hospital. O processo dialogal com cada sujeito durante a produção de dados foi gravado e transcrito na íntegra para posterior utilização na fase de análise dos mesmos.

Por entendermos a pesquisa qualitativa como sendo capaz de juntar tanto a questão de significado, quanto a de intencionalidade presentes nos atos, relações e estruturas sociais do indivíduo ${ }^{(10)}$, nos foi possível fazer a análise temática dos dados oriundos da entrevista e da TCS produzidos pelos sujeitos. Como resultado, foram geradas duas categorias de análise: 1) Concepções e saberes implicados no emprego de práticas integrativas e complementares de saúde por enfemeiros; e 2) Desafios à aplicabilidade de práticas integrativas e complementares por enfermeiros em hospitais.

\section{RESULTADOS E DISCUSSÃO}

\section{Concepções e saberes implicados no emprego de práticas} integrativas e complementares de saúde por enfemeiros

Como vimos, um dos princípios filosóficos que sustentam as PICS é o da integralidade. Seguindo esta lógica, o usuário dos serviços de saúde deve ser visto e entendido como um ser total. Ou seja, ao assisti-lo, o profissional não deve ater-se tão somente à patologia em si, mas a todo o contexto de sua vida e saúde. Isto é, englobar o biológico, o sociocultural, o psicológico e o espiritual, haja vista que a causa da doença não necessariamente se vincula, no todo ou em parte, ao fator biológico ou ao corpo físico, embora muitas vezes se manifeste sob a forma de sinais e sintomas localmente situados.

A concepção de integralidade marcou o discurso dos enfermeiros ao falar sobre as práticas complementares e o conjunto de saberes que as constituem: 
(...) eu acredito que a medicina natural ela consegue trazer a essência da pessoa, então ela integra sujeito; ele e a natureza externa (E2: acupuntura).

Então, a questão da consciência do cuidado de si, você é parte do mundo e o mundo é parte de você (E13: acupuntura).

A integralidade é um termo polissêmico que significa uma abertura ao diálogo e se opõe ao reducionismo e a objetivação dos sujeitos ${ }^{(11)}$. Com isso, possibilita um entendimento melhor da situação real que o cliente esteja atravessando. Esta forma de conceber o ser humano no cuidado esteve presente na fala dos sujeitos como norteadora dos saberes que orientam sua prática:

A pessoa não é um órgão doente, quando ela tem algum órgão que está deficiente, ela está deficiente no todo (...).(E1: Reiki, shiatsu, acupuntura)

(...) porque a gente, na medicina chinesa, a gente vê o sujeito como um todo mesmo, né? Aí eu acho que é o holismo que a gente tanto fala (...) (E2: acupuntura)

(...) na realidade, a avaliação é sempre contextual. É o ser humano e não a patologia propriamente dita. (E10: Reiki)

E eu acho que esse tipo de conhecimento, essa filosofia holística, eles são maneiras de ver o homem na dimensão física, social, emocional e espiritual (...). Eu acho que sustenta muito a minha prática. (E11: terapia floral e Reiki)

Como parte da integralidade, o equilíbrio da energia vital que harmoniza o ser humano sustenta o saber que alicerça as PICS:

(...) o saber biológico, ele contribui, mas eu utilizo o saber que me respalda muito, que é o saber energético. Tem que estar estudando sobre os princípios de energia, pra estar contribuindo cada vez mais com o cliente. (E10: Reiki)

A concepção dinâmica entende saúde como um equilíbrio das forças vitais existentes nas pessoas, enquanto a doença é estabelecida quando há o desequilíbrio dessa interação ${ }^{(11)}$. Muitos fatores podem proporcionar esse desencontro do equilíbrio energético, podendo não ser apenas de natureza física, mas resultante do estresse emocional ou mesmo social. Este se prolonga de tal forma que afeta o equilíbrio das forças vitais, até chegar ao ponto de se exteriorizar, muitas vezes, através de uma patologia. Porém, neste caso, a origem do agravo nada tem a ver com um fator físico propriamente dito, por isso a importância de entender o ponto chave que culminou com o desequilíbrio, a fim de devolver ao corpo seu equilíbrio energético inicial.

Nessa direção, as PICS visam promover o autoconhecimento do indivíduo, o que facilita que a própria pessoa encontre em si mesma seu ponto de equilíbrio. Assim sendo, é importante que os usuários exerçam sua condição plena de sujeitos, partícipes do processo de cuidar:

(...) a resposta é sempre do cliente, ele é o meu material essencial, ele é meu ser essencial (...). (E9: terapia floral)

(...) porque o princípio do processo terapêutico inclui a participação do cliente nesse processo. (E11: terapia floral e Reiki)

O objetivo do caminho trilhado pelas práticas tradicionais é o de realização do cliente enquanto ser humano através de um processo de transformação e realização pessoal como trajetória individual para religar e reharmonizar a pessoa com o cosmo, o mundo, os outros ${ }^{(12)}$ :

Essa energia do "Ying e Yang" tudo o tempo todo em harmonia. E é o que a gente quer estabilizar, quando a gente trata [com acupuntura], quando a gente cuida, a gente quer que essa energia vital, ela esteja harmônica naquele contexto. (E2: acupuntura)

Energia do plano astral caracterizada pelos japoneses como energia Rei e a energia física como energia Ki. Então essa interação ou integração energética faz com que o indivíduo se sinta cada vez mais equilibrado e tenha uma consciência mais plena do seu real processo de vida. (E10: Reiki)

Ela parte do princípio de que o homem tem um corpo energético. As doenças e os sofrimentos físicos não começam no corpo, eles começam num nível mental e emocional. Então é uma visão muito maior, muito mais ampla que leva em conta o princípio energético do ser humano, os corpos energéticos. (E11: terapia floral e Reiki)

O discurso dos enfermeiros demonstrou a importância de se atentar para o equilíbrio e harmonia do indivíduo. Percebemos que o profissional, ao prestar assistência ao usuário, deve atuar não só no corpo físico, mas também nas energias mais sutis que o constituem ${ }^{(13)}$.

Aí quando eu penso neste cuidado complementar, é no sentido de resgatar esse ser integral. (E3: Reiki)

(...) não existe meu corpo e seu corpo, o que existe é energia condensada, que faz seu corpo e o meu corpo. Então, quando você se posiciona, quando você influencia, tem a tríade: energia, matéria e consciência. Então você tem que ter essa visão do todo.... (E4: floral)

(...) os canais que circulam nosso corpo, que faz circular nossa energia mesmo. Essa energia pode nos ajudar a reagir não só para a manutenção da saúde, como também pode nos ajudar para a sua recuperação. (E12: acupuntura)

As PICS visam permanecer em um campo individual e grupal, com o intuito de fortalecer, estimular ou resgatar a saúde 
e a qualidade de vida, resultando em satisfação ao usuário e assim, tendem a mostrar um alto grau de resolutividade ${ }^{(11-12)}$. Além da interação entre sujeito-natureza-cosmos, ressalta-se, também, a importância da interação entre o indivíduo e o meio social, seja com os profissionais de saúde, seja em suas relações interpessoais cotidianas. Tendo em vista que os problemas dos sujeitos são resultados de complexas interações entre mente, corpo e meio social ${ }^{(11)}$, faz-se necessário que tais interações ocorram de maneira bem ajustada. Por tal razão, as PICS visam estabilizar e melhorar essas interações:

(...) eu vejo a medicina chinesa como uma coisa integralizadora, ou seja, que acontece através da interação também de dois seres. A interação de quem cuida e de quem é cuidado. (E2: acupuntura)

(...) a chave de tudo pra mim, quando eu consigo abrir [estabelecer diálogo], é através da relação. (...) Por isso que eu acho que a base do cuidar é o relacionamento. (E3: Reiki)

É oportuno destacar que a interação é um dos elementos que sustentam a relação do cuidado ético e de qualidade, independente do modelo de cuidar adotado pelo profissional. No entanto, face às características próprias da biomedicina e de suas formas intervencionistas que apelam para a objetividade, estas tendem a dificultar o processo interativo e de participação entre ambos os sujeitos envolvidos no cuidado - o profissional e o usuário do serviço de saúde. Em contrapartida, o profissional de saúde quando opta por aplicar uma PICS no cuidado, deve ter a interação como uma de suas bases fundantes.

Desafios à aplicabilidade de práticas integrativas e complementares por enfermeiros no hospital

Um dos aspectos que estão na base de sustentação das PICS é sua concepção sistêmica, segundo a qual todos os fenômenos ou eventos se interligam e se inter-relacionam de forma global e interdependente. Sua aplicação torna-se, portanto, um desafio para o cuidado no âmbito hospitalar, cenário em que geralmente a saúde está sob o domínio biomédico, sendo vista como ausência de doença e sustentada hegemonicamente em saberes e práticas que tendem à fragmentação e à redução do ser humano em suas partes na condução diagnóstica e na terapêutica implementada.

Caracterizam-se pelo uso de meios, por vezes, menos onerosos, com base em uma visão de saúde integral e, principalmente, por métodos não invasivos e não tóxicos. Fundamentadas em um paradigma holístico, essas práticas superam a divisão cartesiana entre corpo e mente através de uma perspectiva que integra esses dois elementos, em uma dimensão em que a mente assume importância vital ${ }^{(11)}$. Portanto, as PICS constituem um grupo de terapias e produtos que não fazem parte da medicina alopática ${ }^{(14)}$. São ditas complementares quando usadas junto com práticas da biomedicina; quando no lugar de uma prática biomédica, alternativas; e, conjuntamente, baseadas em avaliações científicas de segurança e eficácia de boa qualidade, são denominadas integrativas ${ }^{(16)}$.
A capacidade de resolução dos problemas de saúde-doença por estes sistemas de cura se deve de forma fundamental, à diferenciação da interpretação sobre a relação saúde-doença, cujos aspectos psíquicos e físicos não são dicotomizados na busca do restabelecimento do equilíbrio, conforme destaque anterior $^{(7)}$. Tais características os distinguem da abordagem ao ser humano, bem como, dos sistemas de tratamento e cura próprios do modelo biomédico que estão no âmago da formação e atuação dos profissionais de saúde.

Com efeito, os resultados deste estudo indicam que a formação acadêmico-profissional do enfermeiro ainda é fator limitante ao emprego de outras terapêuticas não orientadas pelo modelo biomédico, conforme destacado por 11 dos 15 enfermeiros participantes. Nesse sentido, as características inerentes ao contexto hospitalar dificultam, a princípio, a aplicabilidade de PICS:

Porque na nossa formação por mais que seja integrativa, humanista que é a Enfermagem, a nossa formação é como um carro que a gente tem que ter reposição. Querendo ou não a Enfermagem é influenciada por essa visão cartesiana da saúde, né? (E4: floral)

Então, o que eu acho é que... O que dificulta passa um pouco pela nossa formação, que é calcada no modelo biomédico. E essas terapias, na maioria das vezes, elas tem outro direcionamento, outra sustentação, que é o paradigma vitalício. (E10: Reiki)

À medida que a prática convencional não contempla a complexidade do ser humano em todas as suas manifestações do corpo físico e emocional, emergem as possibilidades da prática convencional ser compartilhada com outras de natureza integrativa. Assim, os discursos dos 15 enfermeiros participantes da pesquisa convergem para o entendimento de que devamos revisitar nossas práticas, refletindo sobre em quê condições se pode pensar no cuidado em uma perspectiva de complementaridade, integrando diferentes métodos e tecnologias de cuidar, tanto os de natureza convencional, próprios da biomedicina, quanto os oriundos das PICS:

A gente finalmente está se dando conta de que o modelo biomédico não dá conta de tudo, a gente precisa de outros conhecimentos. (E11: terapia floral e Reiki)

(...) você vê aí, a medicina chinesa vem sendo extremamente trabalhada, pois é uma medicina voltada totalmente para a natureza, e o mais lindo disso, que podemos viver isso dentro de uma tecnologia, né? Então, nós podemos associar tudo o que nós temos, toda a tecnologia que nós temos hoje, mas não abandonando a sua essência, e essas práticas integrativas, de uma maneira geral, faz com que a gente volte a nossa sensibilidade para isso. (E9: floral)

As PICS inovam na reposição do sujeito doente como centro do paradigma da saúde; na re-situação da relação curador-paciente como elemento fundamental da terapêutica; na 
busca de meios simples, menos dependentes de tecnologia científica dura, porém com igual ou maior eficácia nas situações mais gerais e comuns do adoecimento; na construção de um modelo de saúde que vise acentuar a autonomia do paciente e na afirmação de um saber/prática que tenha como categoria central a saúde e não a doença ${ }^{(15)}$.

Se, por um lado, é inegável a afirmativa de que os avanços biomédicos muito contribuíram com a evolução e melhoria de procedimentos hospitalares, por outro, é fato, também, que a consequência mais visível da fragmentação do ser humano foi o afastamento médico-paciente ${ }^{(2)}$. Situação semelhante ocorre com a assistência de enfermagem e a relação do cuidado em si à pessoa, quando o aparato técnico e tecnológico toma lugar de destaque no cuidar, se distanciando do cuidado expressivo, tão importante quando se objetiva a atenção integral ao ser humano. Tais aspectos resultam em insatisfação difusa e crescente com a abordagem biomédica em virtude de esta ser progressivamente mais impessoal, dedicando pouco tempo à pessoa cuidada, na sua inteireza.

É importante considerar que os motivos da expansão contínua da opção dos usuários por terapias complementares não podem ser limitados apenas às questões de insatisfação ou insucessos das práticas convencionais de saúde. Tal opção fundamenta-se, também, em escolhas culturais e terapêuticas que convergem para transformações nas representações da saúde, doença, tratamento e cura presentes no processo de transformação da cultura(16).

\section{CONSIDERAÇÕES FINAIS}

Em atenção aos princípios filosóficos que norteiam as PICS, os enfermeiros que participaram da pesquisa concebem sua prática de cuidar pautada no entendimento do usuário dos serviços de saúde como seres capazes de interagir e integrar-se socialmente e com a natureza.

$\mathrm{Na}$ ótica desses enfermeiros, o cuidado deve se sustentar para além do biológico, integrando elementos como autoconhecimento, energia e harmonia no plano físico, social e do cosmos no interesse de se alcançar o equilíbrio das forças vitais humanas. O ser humano é um ser complexo, que não se traduz e não preenche sua vida somente com subsídios materiais, precisa ser contemplado em todas as esferas de sua existência, ser nutrido com o alimento, com os relacionamentos, com os projetos realizados, com a qualidade de vida que expresse sua saúde. No entanto, ao longo do tempo, com o avanço técnico-científico e, por conseguinte, a lógica centrada em produção e consumo, o homem vem buscando soluções objetivas para seus problemas, o que acarreta mudança de lógica, de protagonista de sua história à posição de coadjuvante, aplicável, também, ao processo saúde-doença.

Nessa perspectiva, os resultados desta pesquisa reiteram alguns desafios que se apresentam à aplicação de PICS no cuidado, em especial, no hospital, centrados nas características do modelo biomédico que sustentam a formação acadêmico-profissional. Com o desvio do foco de interesse sobre a saúde humana, antes, pautado em forças sobrenaturais, e, posteriormente, em raízes vinculadas ao Renascimento e as mudanças derivadas da revolução técnico-científica o homem passou a ser o centro do universo e a harmonia de sua interação com o todo, deixada de lado.

Entretanto, se este modelo trouxe considerados avanços para a saúde, há de se destacar suas limitações face à complexidade humana e seus componentes de subjetividade que lhe são inerentes, levando à busca de estratégias terapêuticas que possam intervir sob os problemas derivados ou articulados a esses componentes, causadores de doenças. Emergem desses limites as PICS como possibilidades terapêuticas. Embora com propriedades que favorecem o entendimento da totalidade humana e a atuação profissional nessa linha diretiva, há de se refletir que tal evento não garante êxito da aplicabilidade dessas práticas em espaços cujo valor simbólico e repercussões práticas são legitimamente biomédicas, como o hospitalar.

Outra reflexão que se anuncia e se articula a que ora se apresenta são os possíveis deslocamentos dos princípios teórico-filosóficos que regem as PICS em função das influências do modelo dominante, a qual deve ser discutida na academia e nas instituições de saúde.

É oportuno destacar que não se trata de enaltecer uma proposta terapêutica em detrimento de outras, mesmo porque, o pensamento sistêmico que embasa as PICS pressupõe abertura ao diálogo entre diferentes concepções, práticas e saberes. Mas, o que nos parece incoerente e merece atenção de modo a não reproduzir tal postura, é quando um profissional se compromete com uma intervenção integrativa e respalda sua prática seguindo um modelo reducionista. Afinal, o que devemos proporcionar ao usuário como um imperativo ético é a qualidade que imprimimos ao cuidado que desenvolvemos. Se, pautado em um modelo integrativo ou cartesiano, sejamos coerentes e consistentes em nossas escolhas e opções, em atenção, também, àquelas manifestas pelos sujeitos aos quais dedicamos nosso cuidado.

\section{REFERÊNCIAS}

1. Capra F. O ponto de mutação: a ciência, a sociedade e a cultura emergente. São Paulo (SP): Cultura; 1982.

2. Koifman L. O modelo biomédico e a reformulação do currículo médico da Universidade Federal Fluminense. Hist Ciênc Saúde-Manguinhos [periódico na internet]. 2001 Jun [acesso em 17 ago 2011];8(1):49-69. Disponível em: http://www.scielo.br/pdf/hcsm/v8n1/a03v08n1.pdf
3. Cutolo LRA. Modelo biomédico, Reforma Sanitária e a educação pediátrica. ACM Arq Catarin Med [periódico na internet]. 2006 [acesso em 15 ago 2011];35(4):16-24. Disponível em: http://www.acm.org.br/revista/pdf/artigos/392.pdf

4. Alvim NAT, Faria PGF, Ayres A. o diálogo com gestantes sobre plantas medicinais: contribuições para os cuidados básicos de saúde. Acta Sci [periódico na internet]. 2004 [acesso 
em 27 de dez 2011];26(2): 287-294. Disponível em: http:// eduemojs.uem.br/ojs/index.php/ActaSciHealthSci/article/ view/1579/931

5. Ministério da Saúde (Brasil). Portaria $n^{\circ}$. 971, de 03 de Maio de 2006. Aprova a Política Nacional de Práticas Integrativas e Complementares (PNPIC) no Sistema Único de Saúde. Diário Oficial da União 04 maio 2006; Seção 1.

6. Guedes CR, Nogueira MI, Camargo Júnior KR. A subjetividade como anomalia: contribuições epistemológicas para a crítica do modelo biomédico. Ciênc Saúde Coletiva [periódico na internet]. 2006 Dez [acesso em 16 ago 2011];11(4). Disponível em: http://www.scielo.br/scielo.php?script = sci arttext\&pid $=$ S1413-81232006000400030\&lng = en\&nrm $=$ iso\&tlng $=\mathrm{pt}$

7. Tesser CD, Luz MT. Racionalidades médicas e integralidade. Ciência Saúde Coletiva [periódico na internet]. 2008 Fev [acesso em 05 ago 2011];13(1):195-206. Disponível em: http://www.scielo.br/scielo.php?script=sci arttext\&pid $=$ S1413-81232008000100024\&Ing $=$ en\&nr $\mathrm{m}=$ iso\&tlng $=\mathrm{pt}$.

8. Parpinelli MA, Brüggemann OM. Utilizando as abordagens quantitativa e qualitativa na produção de conhecimento. Rev Esc Enferm USP. [periódico na internet]. 2008 Set [acesso em 07 set 2011];42(3): 563-568. Disponível em: http://www.scielo.br/scielo.php?script=sci arttext\&pid $=$ S0080-62342008000300021\&lng $=$ en\&nr $\mathrm{m}=\mathrm{iso} \& \mathrm{t} \operatorname{lng}=\mathrm{pt}$

9. Silva DC, Alvim NAT, Figueiredo PA. Tecnologias leves em saúde e sua relação com o cuidado de enfermagem hospitalar. Esc Anna Nery Rev Enfermm [periódico na internet]. 2008 jun [acesso em 07 set 2011];12(2):201298. Disponível em: http://www.scielo.br/pdf/ean/v12n2/ v12n2a14.pdf

10. Minayo MCS. O desafio do conhecimento: pesquisa qualitativa em saúde. 4. ed. São Paulo-Rio de Janeiro: Hucitec-Abrasco; 1996.
11. Neves LCP, Selli L, Junges R. A integralidade na terapia floral e a viabilidade de sua inserção no sistema único de saúde. Mundo Saúde [periódico na internet]. 2010 [acesso em 14 ago 2011];34(1):57-64. Disponível em: http:// www.saocamilo-sp.br/pdf/mundo_saude/74/07_original_ integridade.pdf

12. Tesser CD. Práticas complementares, racionalidades médicas e promoção da saúde: contribuições poucos exploradas. Cad Saúde Pública [periódico na internet]. 2009 Ago [acesso em 13 ago 2011];25(8):1732-1742. Disponível em: http://www.scielo.br/scielo.php?pid=S0102-311X2009 000800009\&script $=$ sci_arttext

13. Paranaguá TTB, Bezerra ALQ, Souza MA, Siqueira KM. As práticas integrativas na estratégia saúde da família: visão dos agentes comunitários de saúde. Rev Enferm UERJ. [periódico na internet]. 2009 Mar [acesso em 09 ago 2011];17(1):75-80. Disponível em: http://files.bvs.br/ upload/S/0104-3552/2009/v17n1/a013.pdf.

14. Gentil LB, Robles ACC, Grosseman S. Uso de terapias complementares por mães em seus filhos: estudo em um hospital universitário. Ciênc Saúde Coletiva [periódico na internet]. 2010 Jun [acesso em 16 ago 2011];15:1293-9. Disponível em: http://www.scielosp.org/scielo.php?pid= S1413-81232010000700038\&script $=$ sci_arttext

15. Tesser CD, Barros NF. Medicalização social e medicina alternativa e complementar: pluralização terapêutica do Sistema Único de Saúde. Rev Saúde Pública [periódico na internet]. 2008 Out [acesso em 13 ago 2011];42(5):914920. Disponível em: http://www.scielo.br/scielo.php?pid = S0034-89102008000500018\&script $=$ sci_arttext

16. Souza EFAA, Luz MT. Bases socioculturais das práticas terapêuticas alternativas. Hist Ciênc Saúde-Manguinhos [periódico na internet]. 2009 Jun [acesso em 10 ago 2011];16(2):393-405. Disponível em: http:// www.scielo.br/scielo.php?script =sci_arttext\&pid $=$ S0104-59702009000200007 